\title{
Designing Powder Metallurgy Process - The Influence of High Sintering Temperature on Dimensional and Geometrical Precision
}

\author{
Marco Zago ${ }^{(凶)}$, Ilaria Cristofolini, and Sasan Amirabdollahian \\ Department of Industrial Engineering, University of Trento, Via Sommarive 9, \\ 38123 Trento, Italy \\ marco.zago-1@unitn.it
}

\begin{abstract}
The precision of parts produced by Powder Metallurgy (PM) strongly depends on the careful design of PM process parameters. Among them, high sintering temperature is generally considered as detrimental for dimensional and geometrical precision, and therefore neglected in industrial production. Nevertheless, high sintering temperature would strongly improve mechanical characteristics of PM parts, so that the real influence of high sintering temperature on dimensional and geometrical precision is of great interest for PM companies. This study investigates the influence of sintering temperature (up to $1350^{\circ} \mathrm{C}$ ) on dimensional and geometrical precision of real parts. Dimensional changes on sintering and the effect of sintering temperature have been evaluated. Geometrical characteristics have been measured both in the green and in the sintered state, and the real influence of sintering temperature has been highlighted. As a conclusion, it has been demonstrated that the larger shrinkage due to the high sintering temperature is not detrimental with respect to the dimensional precision, being it reliably predictable. Moreover, the influence on geometrical characteristics is unexpectedly low. The encouraging results of this study convinced the main PM companies in Europe to further investigate the influence of high sintering temperature, as partners in a Club Project within the European Powder Metallurgy Association (EPMA).
\end{abstract}

Keywords: Dimensional and geometrical precision - Product development . Precision engineering $\cdot$ Design for powder metallurgy $\cdot$ High temperature sintering process

\section{Introduction}

Dimensional and geometrical precision is one of the most interesting characteristics of Powder Metallurgy (PM) parts, strongly depending on the proper design of the PM process parameters [1-3]. In the conventional press and sinter technology, the green parts are produced by cold compaction in rigid dies and sintered in controlled atmosphere. Dimensional and geometrical precision of green parts is generally very good and may get worse during sintering. Sintering temperature is one of the most critical variables, determining the shrinkage (or swelling) of green parts $[4,5]$. On increasing sintering 
temperature, the larger shrinkage combined with the possible deformation of the parts due to the phenomena occurring at high temperature (creep, viscous flow, phase transformation...) may negatively influence the dimensional and geometrical precision. On the other hand, the positive effect of high sintering temperature on the mechanical properties of porous steels, resulting from the enhanced densification and from the improvement of pore morphology, is well known [6-8]. Better understanding the real effect of high sintering temperature on dimensional and geometrical precision is consequently a priority for PM companies.

This work investigates the influence of high and very high sintering temperature on the dimensional and geometrical precision of industrial $\mathrm{Cr}$ steel parts. Sintering temperatures are higher than those conventionally used in the industrial practice. The shrinkage of dimensions perpendicular and parallel to the compaction direction has been firstly evaluated, aiming at checking any anisotropy of dimensional changes, which is expected on the basis of previous work [1]. Geometrical characteristics in the green and sintered state have been also compared, aiming at distinguishing the influence of the different process steps. Aim of the work is demonstrating that high sintering temperature is not significantly detrimental for dimensional and geometrical precision.

\section{Experimental Procedure}

The dimensions and the geometrical characteristics of the parts studied are shown in Fig. 1. From here on, the parts will be identified as Part 1, the smaller, and Part 2, the larger.
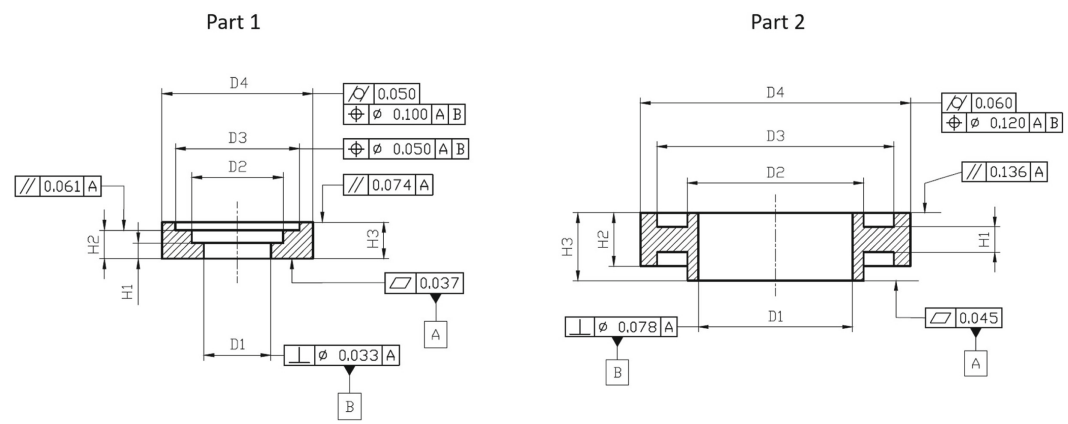

Fig. 1. Parts studied.

The parts were produced compacting a commercial water atomized iron powder pre-alloyed with $3 \%$ wt $\mathrm{Cr}$ and $1.5 \%$ wt Mo, to which $0.8 \%$ wt lubricant and $0.55 \%$ wt $\mathrm{C}$ (graphite) were added. Parts were compacted up to $7.0 \mathrm{~g} / \mathrm{cm}^{3}$ and sintered in vacuum furnace at four different sintering temperatures, higher than the standard ones $\left(1200{ }^{\circ} \mathrm{C}\right.$, $1250{ }^{\circ} \mathrm{C}, 1300{ }^{\circ} \mathrm{C}$, and $1350{ }^{\circ} \mathrm{C}$ ).

Due to confidentiality reasons, neither minor details nor exact dimensions are explicitly reported. The two parts allowed investigating a broad range of dimensions (5 to 
$70 \mathrm{~mm}$ for diameters, 4 to $20 \mathrm{~mm}$ for heights), so that the influence of both sintering temperature and size was highlighted.

Parts were measured both in the green and in the sintered state by a Coordinate Measuring Machine (CMM), scanning mode. Acquired data were processed by MATLAB to calculate the features, from which dimensions and geometrical characteristics were derived, according to the procedure for data processing explained in depth in [9].

\section{Results and Discussion}

\subsection{Dimensional Precision}

Dimensions were grouped in diameters (orthogonal to compaction force), and heights (parallel to compaction force). Dimensional change on sintering was calculated by Eqs. (1) and (2) for diameters and heights, where subscript $g$ and subscript $s$ refer to green and sintered state, respectively.

$$
\begin{gathered}
\varepsilon_{D}=\frac{D_{s}-D_{g}}{D_{g}} \\
\varepsilon_{H}=\frac{H_{s}-H_{g}}{H_{g}}
\end{gathered}
$$

Dimensional change of diameters and heights vs. size are reported in Fig. 2, as affected by sintering temperature.

Dimensional change increases on increasing sintering temperature, as expected, both for diameters and for heights [10]. Anisotropy of dimensional changes is also confirmed, in all the cases dimensional change of diameter is different than dimensional change of height.

Dimensional change is almost unaffected by size for diameters, while for height dimensional change tends to increase on increasing height, and the trend is particularly evident in Part 1 (the smallest one). Further study might prove the role of powder compaction (triaxial stress field, density gradient and ejection procedure) on the different height shrinkage, as proposed in [11]. Nevertheless, dimensional changes can be reliably predicted according to the design procedure defined in previous work $[10,12]$.

\subsection{Geometrical Precision}

Firstly, considering individual features, flatness and cylindricity are evaluated. Results are shown in Fig. 3, where the values measured in the green state and after sintering at the different temperatures are shown. From here on, the green bars will be related to the geometrical characteristics measured in the green state, the blue bars to the geometrical characteristics measured after sintering at the different temperatures, and the red bar to the tolerance.

Flatness slightly worsens on increasing sintering temperature, and same for cylindricity. Larger scatter bands are observed for Part 2, mainly due to the higher geometrical complexity, which makes homogeneous filling more difficult. Nevertheless, measured values are kept lower than tolerances in all the cases. 

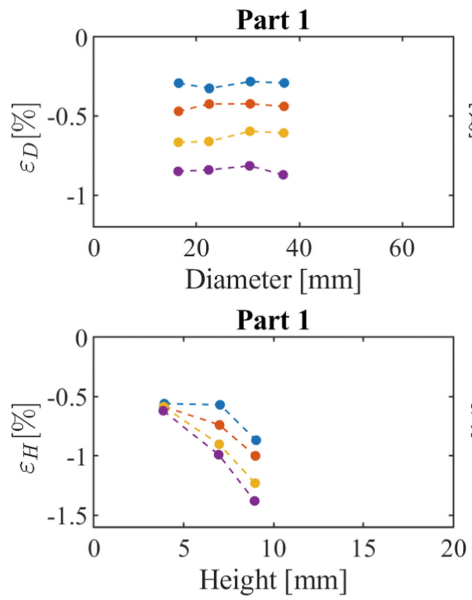

Part 2

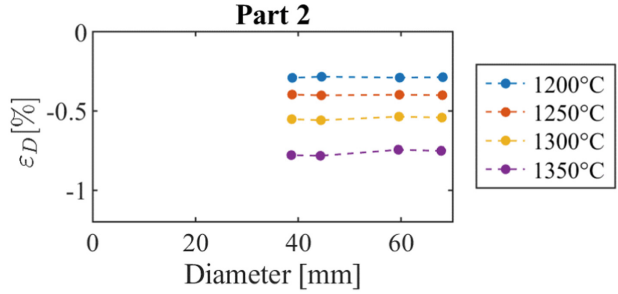

Part 2

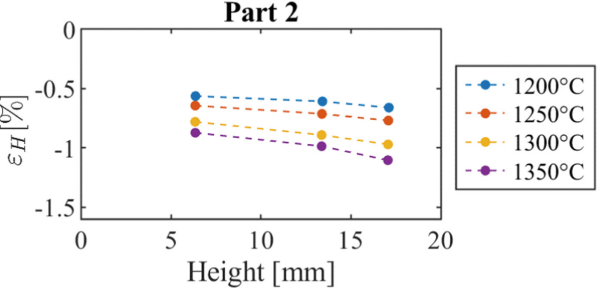

Fig. 2. Dimensional change of diameters (upper) and heights (lower) vs. size at the different sintering temperatures.
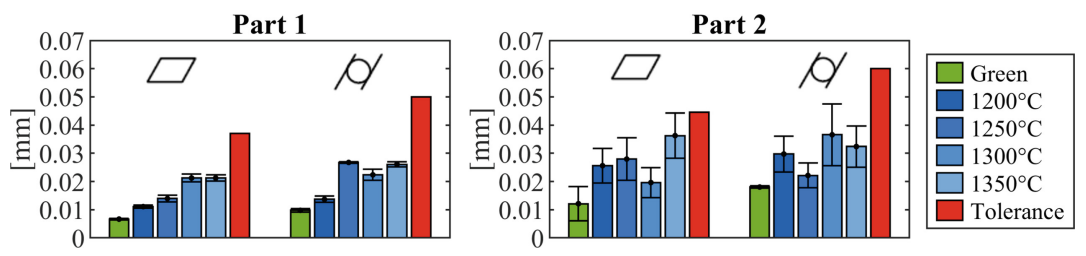

Fig. 3. Flatness and cylindricity in the green state and at the different sintering temperatures for the two parts studied - comparison with the tolerance.

Parallelism, perpendicularity, and co-axiality, both in the green state and at the different sintering temperatures, are shown in Fig. 4. In all the cases, bottom surface in compaction (that is the surface contacting parts holder on sintering) has been considered as primary datum feature. In part 1, according to the drawing shown in Fig. 1, the flatness is identified by the height determining the corresponding surface, and the coaxiality (as by the position tolerance) is identified by the diameter of the corresponding cylindrical surface.

In Part 1, parallelism slightly worsens on increasing the sintering temperature, while perpendicularity is almost unaffected. Coaxiality slightly worsens considering the surface defined by diameter 3 , while no influence is observed for the surface defined by diameter 4 . In all the cases, tolerance is never exceeded.

In part 2, measured values of parallelism are largely scattered, and this is mainly due to the uneven filling sometimes occurring in large parts, given that same scatter is observed in the green part. Tolerance, in terms of mean values, is never exceeded. Perpendicularity is almost unaffected by sintering temperature, but tolerance is exceeded. However, this comes from compaction step, given that perpendicularity measured in the green parts is only slightly worse after sintering. No significant influence of sintering temperature on coaxiality is observed, and tolerance is never exceeded. 


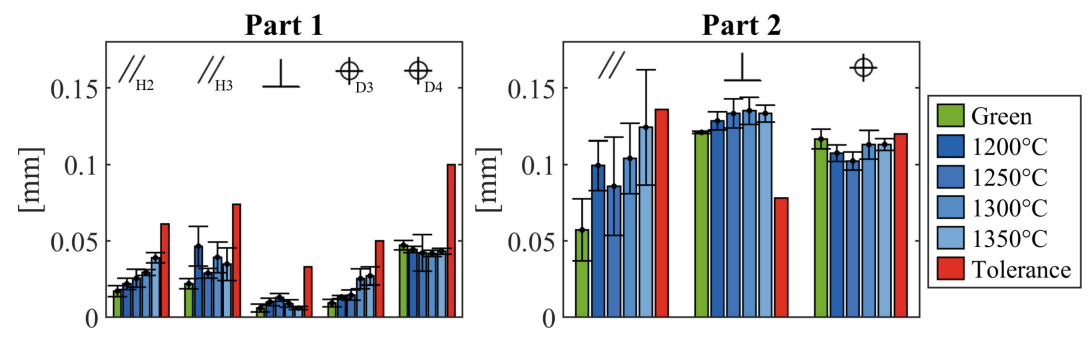

Fig. 4. Parallelism, perpendicularity and coaxiality in the green state and at the different sintering temperatures for the two parts studied - comparison with the tolerance.

Considering Part 2, it can be observed that effort could be required in the compaction step, aiming at improving geometrical characteristics, while the influence of sintering temperature is lower than expected.

\section{Conclusions}

The influence of high sintering temperature, up to $1350{ }^{\circ} \mathrm{C}$, on the dimensional and geometrical precision of low alloyed steel parts has been investigated in this work. Main results are hereafter summarized.

- Dimensional change of diameters increases on increasing sintering temperature, irrespective on size, while dimensional change of height increases on increasing sintering temperature and size, and the effect is more evident for small sizes. As by the design procedure previously developed, this result does not represent an obstacle to sintering at high and very high temperature.

- The influence of high sintering temperature on geometrical characteristics is surprisingly low. The worsening, if any, never determines tolerance exceeding.

- High sintering temperature, determining noticeable improvement in the mechanical properties of sintered parts, can be used without significant detriment of dimensional and geometrical precision.

Further work is in progress within the EPMA Design for Sintering project.

\section{References}

1. Cristofolini, I., Pilla, M., Rao, A., Libardi, S., Molinari, A.: Dimensional and geometrical precision of powder metallurgy parts sintered and sinterhardened at high temperature. Int. J. Precis. Eng. Manuf. 14(10), 1735-1742 (2013)

2. Engstrom, U., Lindberg, C., Tengzelius, J.: Powder and process for high performance PM steels. Powder Metall. 35(1), 67-72 (1992)

3. Griffo, A., Ko, J., German, R.M.: Critical assessment of variables affecting the dimensional behavior in sintered iron-copper-carbon alloys. Adv. Powder Metall. Part. Mater. 3, 221-223 (1994) 
4. Emanuelli, L., Menapace, C., Cristofolini, I., Molinari, A., Larsson, M.: Influence of sintering temperature on shrinkage anisotropy in Cr-Mo low alloy steel green compacts. Adv. Powder Metall. Part. Mater. 05, 99-107 (2014)

5. Takata, J., Nawai, N.: Dimensional changes during sintering of iron based powders. Powder Metall. 38(3), 209-213 (1995)

6. Sanderow, H., Pease, L.: Effect of high temperature sintering conditions on the mechanical properties and microstructure of FLN4-4405 P/M steel. Adv. Powder Metall. Part. Mater. 51-63 (2005)

7. Piotrowski, A., Biallas, G.: Influence of sintering temperature on pore morphology, microstructure, and fatigue behavior of $\mathrm{MoNiCu}$ alloyed sintered steel. Powder Metall. 41(2), 109-114 (1998)

8. Beiss, P., Dalgic, M.: Structure property relationships in porous sintered steels. Mater. Chem. Phys. 67(1-3), 37-42 (2001)

9. Cristofolini, I., Menapace, C., Cazzolli, M., Rao, A., Pahl, W., Molinari, A.: The effect of anisotropic dimensional change on the precision of steel parts produced by powder metallurgy. J. Mater. Process. Technol. 7(212), 1513-1519 (2012)

10. Zago, M., Larsson, M., Cristofolini, I.: An improved design method for net-shape manufacturing in powder metallurgy. In: Lecture Notes in Mechanical Engineering, pp. 257-267 (2020).

11. Zago, M., Cristofolini, I., Molinari, A.: New interpretation for the origin of the anisotropic sintering shrinkage of AISI 316L rings based on the anisotropic stress field occurred on uniaxial cold compaction. Powder Metall. 62(2), 115-123 (2019)

12. Cristofolini, I., Molinari, A., Zago, M., et al.: Design for powder metallurgy - predicting anisotropic dimensional change on sintering of real parts. Int. J. Precis. Eng. Manuf. 20, 619-630 (2019)

Open Access This chapter is licensed under the terms of the Creative Commons Attribution 4.0 International License (http://creativecommons.org/licenses/by/4.0/), which permits use, sharing, adaptation, distribution and reproduction in any medium or format, as long as you give appropriate credit to the original author(s) and the source, provide a link to the Creative Commons license and indicate if changes were made.

The images or other third party material in this chapter are included in the chapter's Creative Commons license, unless indicated otherwise in a credit line to the material. If material is not included in the chapter's Creative Commons license and your intended use is not permitted by statutory regulation or exceeds the permitted use, you will need to obtain permission directly from the copyright holder.

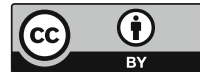

